\title{
Altering the trajectory of early postnatal cortical development can lead to structural and behavioural features of autism
}

\author{
Taylor Chomiak ${ }^{1,2^{*}}$, Vikram Karnik', Edward Block', Bin Hu
}

\begin{abstract}
Background: Autism is a behaviourally defined neurodevelopmental disorder with unknown etiology. Recent studies in autistic children consistently point to neuropathological and functional abnormalities in the temporal association cortex (TeA) and its associated structures. It has been proposed that the trajectory of postnatal development in these regions may undergo accelerated maturational alterations that predominantly affect sensory recognition and social interaction. Indeed, the temporal association regions that are important for sensory recognition and social interaction are one of the last regions to mature suggesting a potential vulnerability to early maturation. However, direct evaluation of the emerging hypothesis that an altered time course of early postnatal development can lead to an ASD phenotype remains lacking.

Results: We used electrophysiological, histological, and behavioural techniques to investigate if the known neuronal maturational promoter valproate, similar to that in culture systems, can influence the normal developmental trajectory of TeA in vivo. Brain sections obtained from postnatal rat pups treated with VPA in vivo revealed that almost $40 \%$ of cortical cells in TeA prematurely exhibited adult-like intrinsic electrophysiological properties and that this was often associated with gross cortical hypertrophy and a reduced predisposition for social play behaviour.

Conclusions: The co-manifestation of these functional, structural and behavioural features suggests that alteration of the developmental time course in certain high-order cortical networks may play an important role in the neurophysiological basis of autism.
\end{abstract}

\section{Background}

Autism spectrum disorder (ASD) is a behaviourally defined brain disorder affecting approximately 1 in 150 children [1]. Autistic children exhibit impoverished verbal and non-verbal communication skills and reduced social interactions where they often bias their attention towards certain objects rather than the surrounding social situation [2]. Children with ASD also display behavioural impairments in attention engagement and disengagement, do poorly in emotional discrimination and facial recognition, and fail to response to their own names [2-6]. It has been suggested that behavioural phenotypes of ASD are associated with maturational

\footnotetext{
* Correspondence: tgchomia@ucalgary.ca

'Department of Clinical Neurosciences, Hotchkiss Brain Institute, Faculty of Medicine, University of Calgary, Calgary, Alberta, T2N 4N1, Canada Full list of author information is available at the end of the article

changes in cortical thickness and organization, particularly affecting pyramidal neurons [1,7]. In addition, structural and functional abnormalities are particularly prominent in the temporal neocortex $[1,8-10]$, and associated target structures including the amygdala [3], that mediate auditory and visual object recognition and attention orientation [1,11-14].

The underlying cellular and neurobiological mechanism(s) associated with ASD have remained elusive. Based on the work in autistic children, Susan Bryson has proposed that the expression of autistic behaviours may involve a hypersensitivity to sensory stimulation [6]. Indeed, recent work using one rodent model of autism has provided some evidence to support this conjecture. For example, Markram's lab has shown that rats prenatally exposed to VPA frequently exhibit hyper-connectivity and enhanced plasticity in prefrontal neocortical 
networks $[15,16]$. Hence, from a cellular level, increased neural activity in cortical networks may lead to abnormally noisy networks thus making it difficult for neural processing of certain sensory stimuli in the autistic brain [17].

The postnatal maturation trajectory of the neocortex is highly heterogeneous, exhibiting large regional variability in both structure and functional development [18-22]. This issue is, however, rarely addressed in the literature despite the fact that there is a growing realization that some of the key brain abnormalities of autism can be highly protracted and continue to evolve during postnatal life $[23,24]$. This is not surprising given the fact that certain high-order brain regions important for social functions endure continued plastic changes and delayed postnatal maturation [25,26]. For example, unlike some regions of the primary sensory and motor cortices, the speed of cortical maturation in high-order temporal association networks is significantly slower, often extending into adolescence [18-22]. This developmental feature suggests that the trajectory of temporal lobe development may be particularly sensitive to pathogenic factors that can influence the speed of neuronal maturation, especially during postnatal life [27]. For example, culture work has shown that valproate (VPA), and analogous compounds, are potent epigenetic factors that can facilitate neuronal maturation in neurons [28-30]. However, whether VPA can influence the speed of postnatal maturation in vivo and whether this can be associated with structural and behavioural characteristics related to autism remains unknown.

Here we address the emerging hypothesis that it may be the time course of postnatal cortical development that is most disturbed in ASD. To this end, we examined the TeA network from animals treated with a VPA dosage previously used in vivo [31]. We found that in addition to premature electrophysiological development of individual TeA cells, treated animals can exhibit gross cortical hypertrophy and a reduced predisposition for social play behaviour.

\section{Results}

Reduced social (play) interaction associated with VPA treatment

The most prominent feature of autism is social impairment [2]. We therefore first examined whether VPAtreated animals also exhibited a similar behavioural pattern. We choose to investigate social play behaviour since it is one of the most widespread and least ambiguous forms of play amongst mammals [32]. As shown in Figure 1, we found a significant reduction in the number of rough-and-tumble play behaviours in VPA-treated animals as compared to age-matched (P35-37) controls (Figure 1A-B; Mann-Whitney $U=0 ; \mathrm{p}<0.05 ; \mathrm{n}=8,2$ sessions with 4 animals). For example, there was a reduction in the number of "attacks to the nape" and "pins" in treated rats relative to controls ([32] also see Methods). It is possible that reduced play behaviour following VPA-treatment may occur as a result of abnormal physical development under the rearing conditions for treated animals. To examine this, we first monitored eye opening time. As previously reported [17], we noticed a small but significant delay in eye opening by 1-2 days in treated rat pups (Figure 1C; two-way ANOVA Bonferroni post-test $t \geq 3.246$ on day $10-12$ and $\mathrm{t} \leq 1.357$ for all other days; $\mathrm{p}<0.05 ; \mathrm{n}=14$ and $\mathrm{n}$ $=17$ for control and treated animals respectively), well before behavioural testing was undertaken. Second, we also measured changes in body weight between control and treated groups during the first month of life but did not observed any obvious difference between the two groups (Figure 1D; two-way ANOVA Bonferroni posttest $\mathrm{t} \leq 1.244 ; \mathrm{p}>0.05 ; \mathrm{n}=14$ and $\mathrm{n}=17$ for control and treated animals respectively). Finally, since VPA has previously been shown under some conditions to lead to generalized motor impairments in rodents [33], we tested to see if the reduced level of social play could be explained by general motor deficits. To this end, both VPA-treated and control animals underwent training and learned (two-way ANOVA $\mathrm{F}(7,152)=13.2$; $\mathrm{p}<$ 0.001 ) a cue-dependent reward-based sensorimotor task (see Methods for details). As shown in Figure 1E, VPAtreated animals were on par or even slightly better than controls at learning the association between the cue and the reward in addition to retrieving the reward (Figure 1E; two-way ANOVA Bonferroni post-test for session 1 $\mathrm{t}=3.331 \mathrm{p}<0.01$ and for all other sessions between treated and control groups $\mathrm{t} \leq 2.265 ; \mathrm{n}=6$ animals). Furthermore, extinction of the learnt task (two-way ANOVA $F(7,106)=16.99 ; \mathrm{p}<0.001$ ) was also similar between controls and VPA-treated animals (Figure 1F; two-way ANOVA Bonferroni post-test $\mathrm{t} \leq 1.774$; $\mathrm{p}>$ $0.05)$. Taken together, these data indicate that the observed reduction in play behavior was unlikely due to general physical and/or rearing conditions [34]. Since rough-and-tumble play behaviour is a well-established measure of play initiation and social interaction [32], our data suggests a reduced predisposition for social interaction in VPA-treated animals.

\section{Enlarged temporal association cortex in VPA-treated animals}

Since the temporal lobe is important in visual attention and social interaction $[1,35,36]$, it is therefore not surprising that that many neuropathological findings with respect to the autistic brain are often associated with the temporal lobe region [8,9]. For example, evaluation of some autistic brains has revealed an increase in 
A
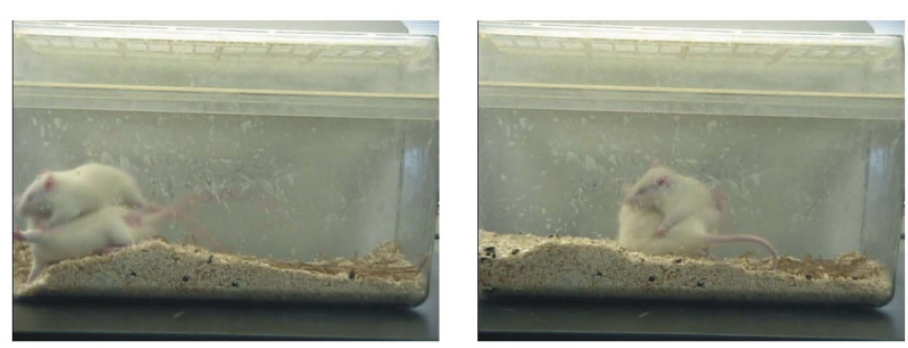

B

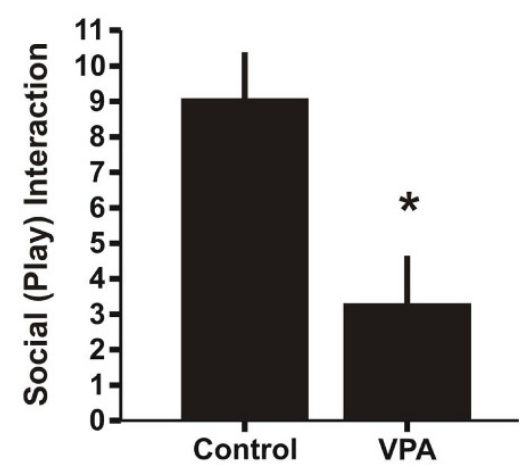

C

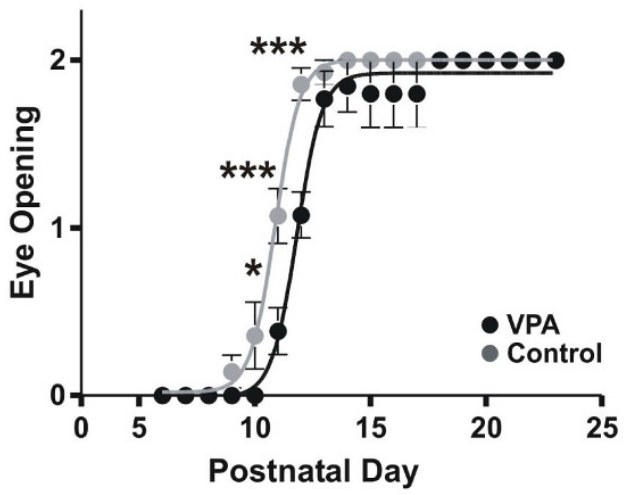

$\mathbf{E}$

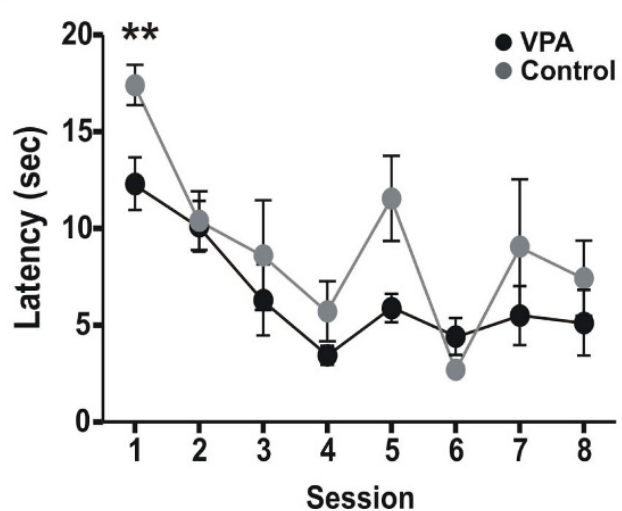

D

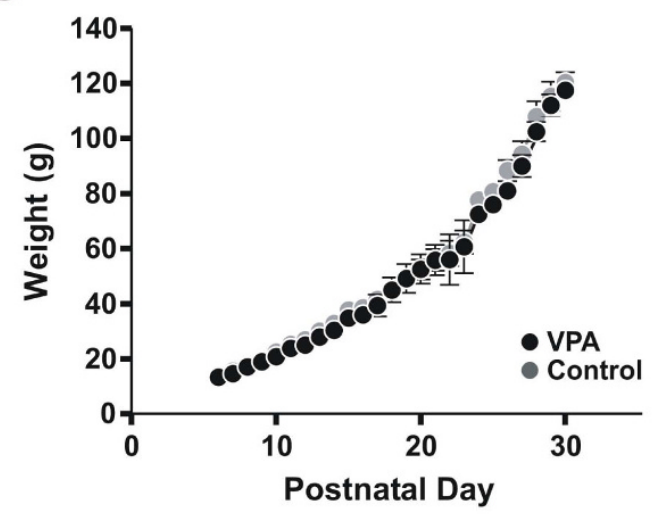

F

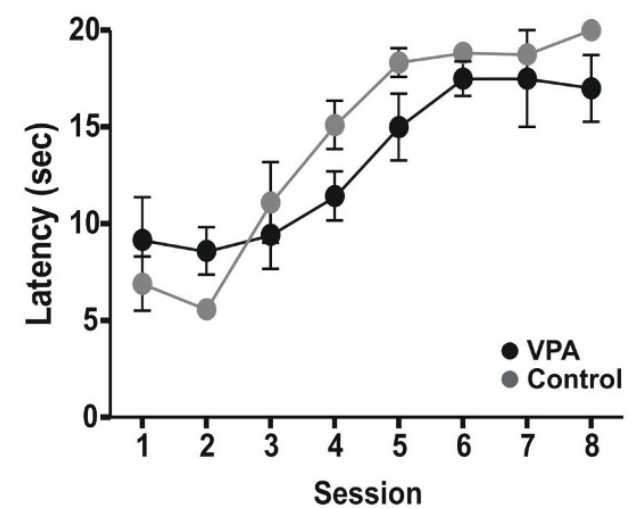

Figure 1 Behavioural features associated with VPA-treatment. A: Typical examples of rough-and-tumble play behaviours, a measure of play initiation and social interaction [32]. The left panel illustrates an "attack" (animal on top) to the nape and the right panel a "pin" by the rat. B: Summarized data of rough-and-tumble play behaviours scored in a ten minute test session between control and VPA-treated animals. ${ }^{*} p<0.05$. C: significant delay of about $1-2$ days $(p<0.05)$ in eye opening between control and VPA-treated animals. Eye scoring, similar to that defined previously [17], is as follows; 0 closed, 1 half-open, 2 complete eye-opening. D: Rat pup body weight between groups (i.e. control and VPAtreated) during the first month of life beginning on the first day of injection (P6). There was no obvious difference between groups ( $p>0.05$ ), an indicator of normal physical development under the rearing conditions for treated animals [34]. E: Cue-dependant associative learning for both VPA (black) and control (grey) animals. Rats were on a $47.5 \mathrm{~h}$ water deprivation schedule prior to training sessions. Animals were placed in the test cage and a $10 \mathrm{kHz}$ sine-wave tone (5 pulses of 1 second in duration at $1 \mathrm{~Hz}$ ) was present at random time points once the animal was in the opposite half of the cage relative to the reward location. Only when the $10 \mathrm{kHz}$ tone was presented, was the reward (30\% sucrose solution) available. Latency measurements represent the time between cue onset and arrival and orientation to the fixed reward location. F: Same protocol as in $\mathrm{A}$, but now when the $10 \mathrm{kHz}$ tone was presented, it was not reinforced (i.e. no reward was available). See Methods for more details. ${ }^{*} p<0.05 ;{ }^{* *} p<0.01 ;{ }^{* *} p<0.001$. 
cortical grey matter and an enlargement of some regions of the temporal lobe by about $5-10 \%$ relative to typically developing controls $[9,10]$. Thus, to see if a similar histological pattern could be observed in our model, we examined TeA cortical grey matter thickness in VPAtreated and control animals similar to that done previously [37]. Although not clearly evident in all animals, we found a marginally significant increase in cortical thickness of just under 10\% between age-matched (P2023) treated and control animals (Figure 2; paired t-test $t$ $=3.255 ; \mathrm{p}<0.05 ; \mathrm{n}=8$ animals). Hence, this structural change in cortical anatomy resembles that observed in the human autistic brain, possibly reflecting an accelerated time course in cortical development [1].

\section{Accelerated development in the TeA network}

Previous work has shown that infragranular layers in the rat TeA consist of many slowly maturing pyramidal neurons [38]. Indeed, electrophysiological recordings have also shown that many infragranular TeA neurons in juvenile cortex (i.e., < 1 month) have not yet acquired adult-like intrinsic membrane properties (see Figure 3A for example) [39]. To examine the possibility of an accelerated time course of TeA development, we examined the intrinsic electrophysiological properties of individual cells which are known to undergo well characterized hallmark changes during development $[40,41]$. To this end, we obtained a total of 44 infragranular whole-cell recordings $(\mathrm{n}=26$ treated; $\mathrm{n}=18$ control) from juvenile VPA-treated and control animals. We found that the network contained significantly more cells with adult-like intrinsic neuronal properties in VPA-treated than saline or untreated control animals, including many neurons exhibiting intrinsic membrane excitability and spontaneous synaptic activities (Figure
3A). Using electrophysiological features as an index of neuronal maturation, we found that juvenile VPA-treated animals had a significantly higher number of maturing neurons as compared to control animals (Figure 3B; Mann-Whitney $U=0 ; \mathrm{p}<0.05)$. Hence, these data indicate a temporally accelerated pattern of neuronal development as a result of VPA-treatment.

\section{VPA does not appear to lead to cell death or the abnormal electrophysiological development of individual neurons}

Although VPA treatment has been shown to promote neuronal maturation [28], its effect on cortical neurons may also involve tissue toxicity, cell injury and death [42]. To exclude these possibilities, we first conducted DAPI cell counts and found no evidence of cell loss due to VPA treatment (Figure 4; Mann-Whitney $U=4$; p > $0.05 ; \mathrm{n}=6$ animals). In fact, we noted a slight increase in cell number. In the second set of experiments we examined whether VPA can have a non-specific injury type of an effect on the membrane properties of TeA neurons. Of the five basic intrinsic membrane properties examined, all but one was similar between the two groups (Figure 5; membrane potential $\left(\mathrm{V}_{\mathrm{m}}\right)$, MannWhitney $U=17$; spike threshold, Mann-Whitney $U=$ 15; spike amplitude, Mann-Whitney $U=14$; input resistance $\left(\mathrm{R}_{\mathrm{in}}\right)$, Mann-Whitney $U=16 ; \mathrm{n}=12$ neurons). Only the membrane capacitance appeared to be smaller in treated animals relative to controls (Mann-Whitney $U=5 ; \mathrm{p}<0.05)$. However, this reduction can not be considered abnormal given the fact that it was still several-fold larger than immature neurons and comparable to some spiking cells in control animals (data not shown). Taken together, these data suggest that the effect of VPA on network and cellular development is
A
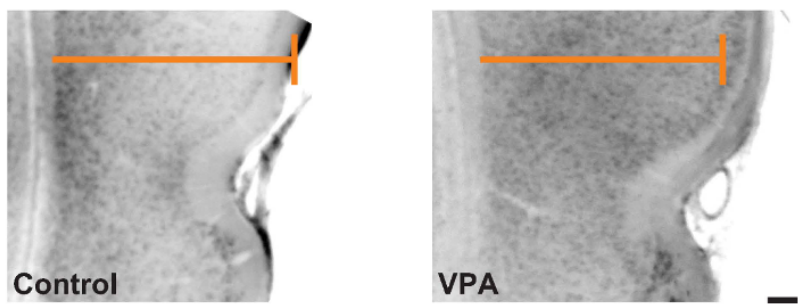

B

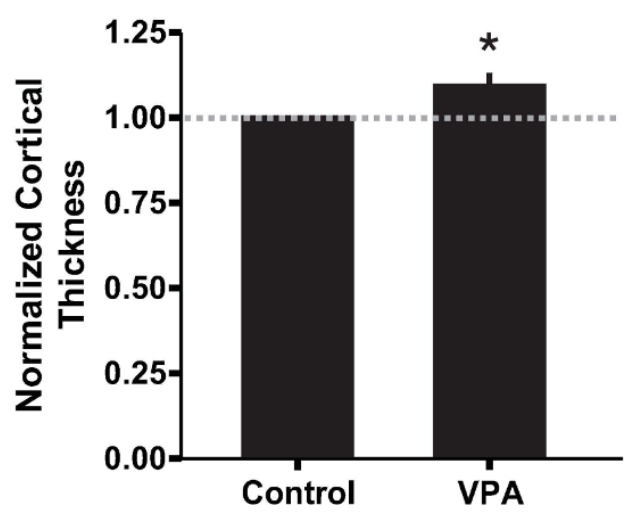

Figure 2 Enlarged temporal association cortex in VPA-treated animals. A: Images of the TeA area, located dorsal to the rhinal fissure (indent), for both control (left) and VPA-treated animals (right) illustrating an increase in cortical thickness in the latter. Note that the coloured line is identical for both images for reference. Scale bar $=200 \mu \mathrm{m}$. B: Normalized cortical thickness measurements of the TeA area between control and VPA-treated animals. ${ }^{*} \mathrm{p}<0.05$ 
A

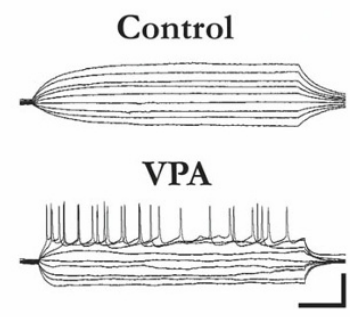

Control

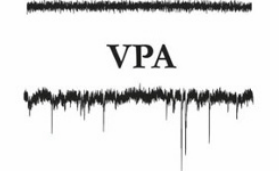

B

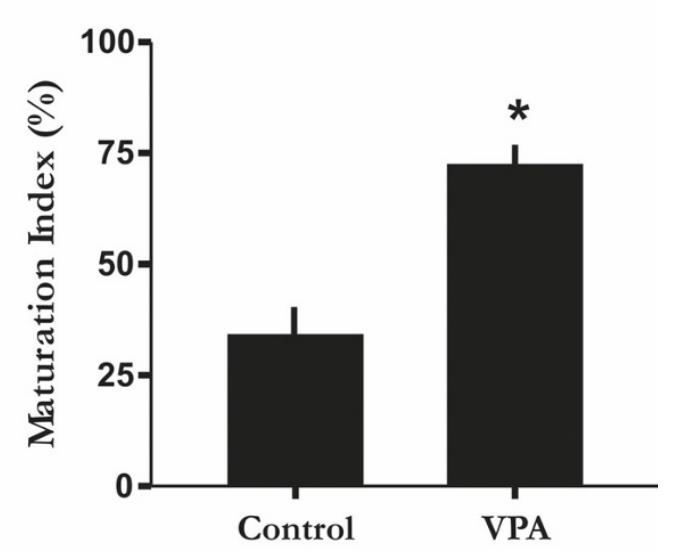

Figure 3 Accelerated development of the TeA network in juvenile animals. A: The majority of cells in treated animals exhibited adult-like electrophysiological properties and spontaneous synaptic activity ("VPA"), and is in stark contrast to that observed in saline or untreated control animals ("control"). The majority of these cells exhibited immature intrinsic neuronal properties similar to that found in new born rats [41]. Voltage responses to a current step protocol were applied from a holding or resting potential of around -60 to -70 mV. In voltage-clamp, cells were clamped at $-60 \mathrm{mV}$. Sale bars: $30 \mathrm{mV}$ vertical and $150 \mathrm{~ms}$ horizontal for top two traces; and $15 \mathrm{pA}$ vertical and 400 ms horizontal for bottom two traces. B: Based on the intrinsic membrane properties (see panel A for example), juvenile ( $<1$ month) VPA-treated animals have a significantly higher maturational index as compared to juvenile control animals. ${ }^{*} \mathrm{p}<0.05$.

unlikely due to deleterious effects on neuronal viability and functional integrity.

\section{Discussion}

\section{Experimental approach}

VPA has previously been associated with ASD based on the fact that children born to pregnant women taking VPA for seizure management had an elevated risk of developing ASD [15,43]. However, although some of the abnormalities observed in the autistic brain are of prenatal origin, postnatal factors are also considered to play an important role [23,27]. In fact, very little research has attempted to address how chemical agents may influence certain postnatal developmental processes [27]. In our model, the adverse effect of VPA may be derived from a persistent effect on the temporal lobe as it undergoes a protracted and delayed maturation. For example, VPA has been frequently used in infants to manage seizure [44]. Nevertheless, the importance of our experimental approach is that it has allowed us to directly examine the emerging hypothesis that it is an altered time course of brain development that is most disturbed in autism [1].

The timing of brain insult also seems to differ in terms of the phenotypes of ASD. For example, later exposure in humans has largely been associated with the nonsyndromic and sometimes high-functioning forms of ASD [45]. By contrast, early exposure to an insult (e.g. first trimester) represents the time when the syndromic (i.e., multiple congenital anomalies and mental
A

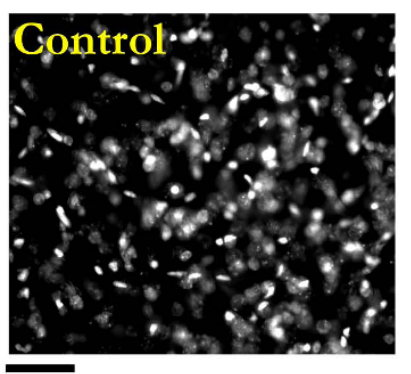

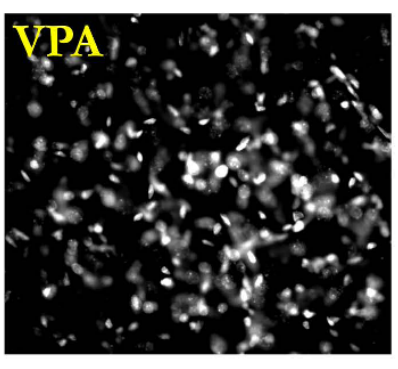

B

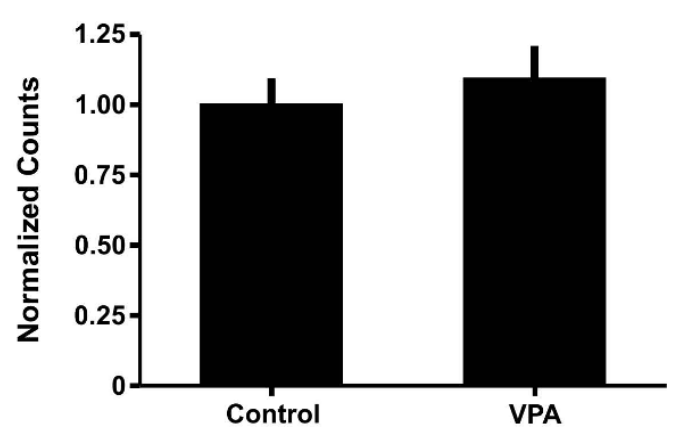

Figure 4 Lack of cell loss due to VPA treatment. A: Typical images of control and VPA-treated tissue sections illustrating a comparable pattern of DAPI staining. Scale bar $=50 \mu \mathrm{m}$. B: Summarized cell count data showing that there is no significant cell loss between control ( $n=3$ animals) and VPA-treated animals ( $p>0.05 ; n=3$ animals). DAPI counts were conducted age-matched littermates. 


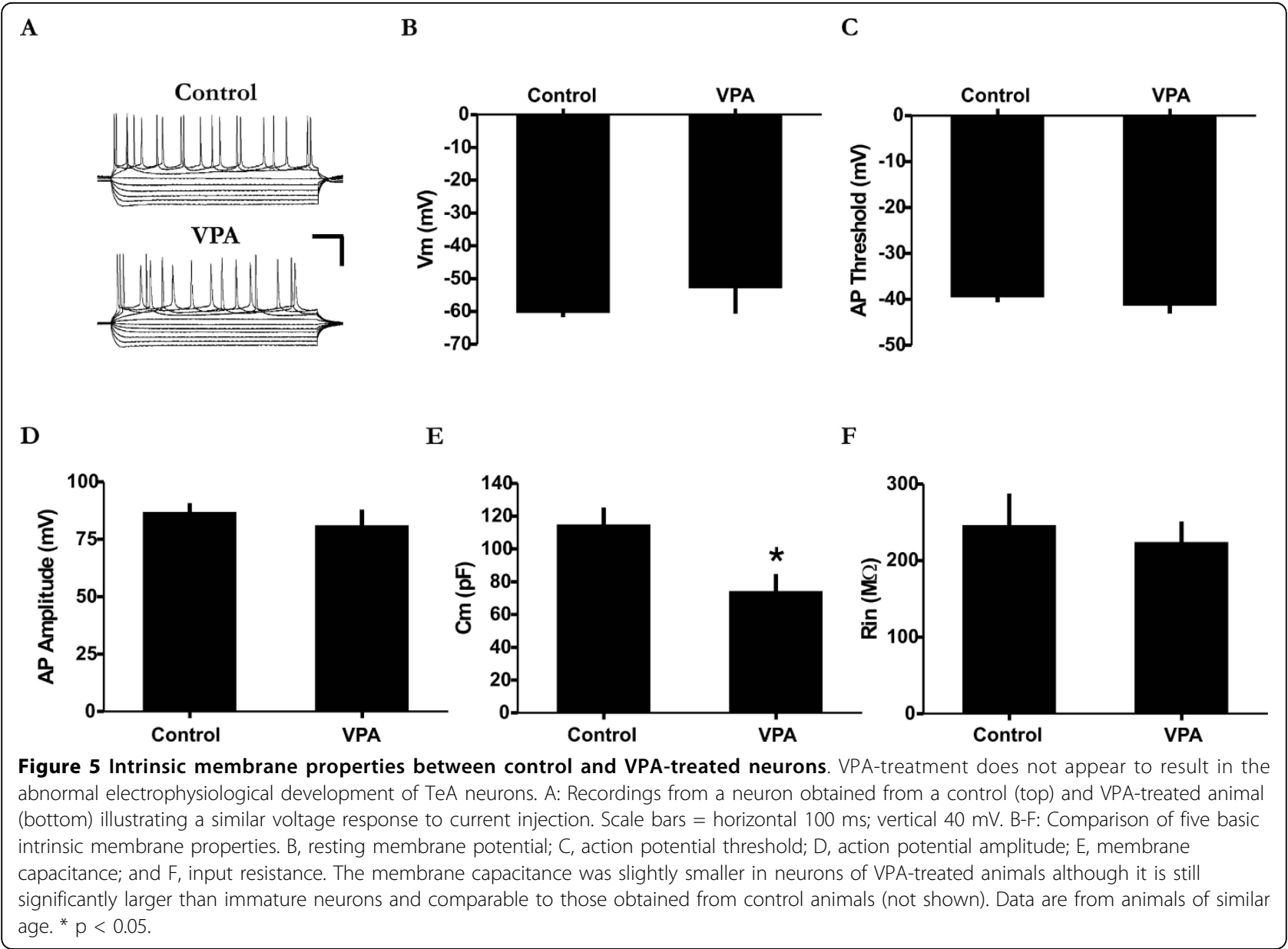

retardation) form of ASD is thought to be initiated [45]. In this regard, the main physical developmental delay we observed here is a short delay in eye opening (see Figure 1) as reported previously [17]. However, in an exceptional case, we found one pup among all littermates that had a persistently low body weight and delayed fur growth during early postnatal development which was excluded from our analysis. Interestingly, a persistently low body weight was also noted in most (if not all) animals in a previous study using an early prenatal VPA treatment protocol [17]. Hence, the temporal difference between VPA treatment may produce certain biases related to behavioural and developmental phenotypes [33] in which later insults may more closely reflect nonsyndromic high-functioning forms of autism.

\section{Cortical structural and electrophysiological changes induced by VPA}

The most consistent neuropathological finding with respect to the autistic brain is cortical enlargement, particularly in the temporal lobe region [8,9]. This is not surprising since the temporal lobe association networks are involved in many processes including attention, social interaction, object recognition, and biased competition where the object's neural representation dominates across multiple networks [1,11-13,35,46,47]. Postmortem examination of some autistic brains has revealed an increase in cortical grey matter and hyperconvolution of some regions of the temporal lobe [8]. In particular, Piven and colleagues noted that the largest relative increase in cortical grey matter was in the temporal lobe [9]. Their value of around a 5\% increase in the temporal lobe for typically developing controls is consistent with our results (Figure 2) and that of a recent study by Schumann and coworkers of around $10 \%[10]$.

The mechanism through which VPA influences neuronal development and cortical thickness is still not entirely clear and is likely complex and multifactorial. Although VPA is classically considered an anti-epileptic drug, a more recent study has shown that VPA appears to have a strong influence in mediating epigenetic modulation rather than enhanced GABA activity [31]. Indeed, in our study the accelerated appearance of 
adult-like membrane properties in VPA-treated animals was obtained at a dosage that has been shown to inhibit histone deacetylases in vivo and activate epigenetic signalling pathways in the rat [31]. These data indicate a possible role of chromatin remodelling in the control and execution of developmental gene programs involved in different aspects of neuronal maturation [28-30,48]. However, future study is required to determine whether potential changes to the intracellular somatodendritic lipid and/or protein organization which may be contributing to the immature electrophysiological phenotype can also be related to the emergence of mature intrinsic properties $[49,50]$. Nevertheless, in vivo VPA-treatment does appear to facilitate premature development of the TeA network. Interestingly however, inactivation of PTEN signalling mechanisms can also lead to increased cortical thickness [37], while mutations leading to the formation of tuberous sclerosis complex, which is strongly associated with ASD [51], can also result in more active cortical networks in both humans and rodents [52-54]. Thus, VPA may exert its effect on neuronal development and cortical anatomy through activation of gene programs related to activity development [29] and/or activity-dependent processes and signal transduction mechanisms $[37,55,56]$.

\section{VPA-induced behavioural changes}

As noted by Leo Kanner in 1943, autistic children tend to avoid social interaction [2]. Over the past several years, different indices of social interaction in animal models have been investigated and are consistently found to be reduced $[17,37,57]$. Social play behaviour has been well documented in the rat and is also considered one of the most widespread and least ambiguous forms of play amongst mammals [32]. However, this type of social interaction, to our knowledge, has never previously been evaluated in relation to an autistic phenotype under these conditions.

It is well recognized that high-order temporal lobe networks play a critical role in auditory and visual processing, attention, and ultimately, social interaction [1,11-14,35,36,47,58-60]. Autistic children often have difficulty with attention disengagement $[5,6]$ and frequently fail to react to their names so much so that parents often suspect deafness [61]. Hence, the reduced social play behaviour we report here may reflect complex functional impairments in multiple sensorimotor domains. Indeed, a recent study has shown that the TeA network in rats can form a descending reticular-like network, providing top-down innervations to many cortical and subcortical structures including the amygdala [46]. Thus, premature development of even a small population of TeA neurons may have a powerful influence on many downstream structures that are also involved in working memory, attention, and emotional behaviours.

\section{Conclusions}

The main finding of the present study indicates that early postnatal exposure to VPA, at a dosage known to inhibit histone deacetylases in vivo [31], can lead to synchronous developmental alterations reminiscent of ASD. Neurons from VPA-treated animals tended to acquired adult-like electrophysiological properties sooner during early postnatal development relative to controls. Furthermore, these electrophysiological changes were also associated with an increase in cortical thickness and a reduced predisposition for social interaction. Such a co-manifestation of features is consistent with the emerging theory that it is the time course of early postnatal development that may be most disturbed in ASD [1].

\section{Methods}

\section{Preparation and electrophysiology}

All experimental protocols were approved by the University of Calgary Conjoint Faculties Research Ethics Board. Under this protocol, animals are housed in The University of Calgary Animal Resource Center facility receiving constant care throughout the year. Briefly, newborn male and female Sprague-Dawley rats were socially caged after weaning at day P21. Frontal tissue sections were prepared on a Leica vibrotome (Germany). Slices $(\approx 300 \mu \mathrm{m})$ were submerged in a recording chamber in oxygenated $\left(95 \% \mathrm{O}_{2} ; 5 \% \mathrm{CO}_{2}\right)$ artificial cerebrospinal fluid (aCSF). The aCSF had a final $\mathrm{pH}$ and osmolality of around 7.4 and 290-300 $\mathrm{mOsm} / \mathrm{kg}$ respectively and contained (in $\mathrm{mM}$ ): $\mathrm{NaCl}, 110 ; \mathrm{KCl}, 3.5$; $\mathrm{MgCl}_{2}, 1.5 ; \mathrm{NaHCO}_{3}, 26 ; \mathrm{CaCl}_{2}, 2$ and glucose, 10. The patch electrode solution contained (in $\mathrm{mM}$ ): K-gluconate, 120; KCl, 10; Na-HEPES, 10; Na-GTP, 0.2; NaATP, 4. Whole-cell patch-clamp recordings were targeted to layer $\mathrm{V}$ of the posterior sector of the TeAectorhinal cortex (also known as TeV). The TeA region is identified, under DIC microscopy, as the region located dorsally to the rhinal fissure $[62,63]$. The patch electrode solution had an osmolality and $\mathrm{pH}$ of around 285 mOsm and 7.2 respectively. The DC resistance of patch electrodes was 6-8 $\mathrm{M} \Omega$ and recordings were made at $30-33^{\circ} \mathrm{C}$. The bridge-balance and liquid-junction potential were corrected on-line. Intrinsic membrane properties were determined according to methods previously described [64].

\section{in vivo valproate injections}

The sodium salt of VPA (NaVPA; Sigma-Aldrich, St. Louis, MO) was dissolved in $0.9 \%$ saline $(\mathrm{pH} \approx 7.3)$. Treated rats received a single i.p. injection on the order of $150 \mathrm{mg} / \mathrm{kg} /$ day [31]. It should be noted that due to 
the species variation in valproate metabolism, direct dosage correlations can not be made with humans [65]. However, from these data, we may predict that the functional dose in rat models of seizure would be slightly higher than that of humans, which is indeed the case $[42,44,66]$. Injections started on P6 and then continued for a maximum of 2 weeks. We also injected littermate control rats with $0.9 \%$ saline $(\mathrm{pH} \approx 7.3)$. Recordings were made from juvenile ( $<1$ month) animals ranging from P12-P26.

\section{Social (play) behaviour}

Animals were isolated in macrolone cages measuring 43 $\mathrm{cm} \times 15 \mathrm{~cm} \times 28 \mathrm{~cm}$ for a period of 24 hours prior to testing similar to previously described [17]. The test consisted of placing two rats (either saline injected or VPA injected) into the test cage for a period of $10 \mathrm{~min}$ utes. The animals (male/female pairs) were tested at the same age (i.e., age-matched littermates ranging from P35-P37) and weight ( $\pm 20 \mathrm{~g})$ as each other. Rough-andtumble play behaviors (e.g., a direct "attack" to the nape on the neck of the other rat or "pinning" where one of the animals is lying with its dorsal surface on the floor of the test cage with the other animal standing over them), were measured as an indicator of social interaction [32].

\section{Cued sensorimotor task}

A total of 6 male and female animals (3 pairs; sex and age-match littermates) were used. Animals were water deprived for $47.5 \mathrm{~h}$ prior to behavioural testing but had unrestricted access to food. Following each session, animals had unrestricted access to water for $0.5 \mathrm{~h}$. Training sessions consisted of $\geq 3$ trials and began on postnatal day 23-30. Training occurred in the same test cage with an approximate 3-5 min break between trials. This also allowed for the paper towel bedding of the test cage to be replaced following each trial. The experiments were conducted in an isolated quiet room or sound-attenuating chamber and the location did not change once training had begun. The test cage consisted of a macrolone cage with a hole drilled a few centimeters from the bottom at one end (fixed reward location) just large enough to permit insertion of a water bottle spout. The wall was covered so the animal could not see the bottle contents that the spout was attached to. Latency measurements represent the time difference between auditory cue presentation and arrival at, and orientation to, the fixed reward location. A maximum cut-off of 20 seconds was used. A spout was always present but only when the cue was presented and the animal arrival at and orientated to the fixed reward location was the $30 \%$ sucrose solution available. A computer with a National Instruments
A/D board (NI DAC-Card 6024E, $200 \mathrm{kSamples} / \mathrm{s}, 16$ channels), a breakout box (National Instruments BNC2020), and a high speed IEEE 1394a port was used to run in-house software to collect timing information. A simple on/off switch was connected to the computer to trigger synchronization between the tone output and latency measurements. The software generated a $10 \mathrm{kHz}$ 80-85 dB sin wave output played through speakers placed at a short and fixed distance from the cage. The software recorded the button press, started the audio signal, and recorded the second button press when the rat touched the reward (i.e. water bottle spout). The time from the first button press to the second was logged in a data file and presented as a temporal latency.

\section{Cortical thickness measurements and DAPI staining}

Age-matched littermate brains from juvenile animals (e. g. P20-P23) were removed and fixed in $4 \%$ PFA overnight at $4^{\circ} \mathrm{C}$. Frontal sections $(150 \mu \mathrm{m})$ were then cut on a Leica vibrotome (Germany) in PBS. Images were acquired with a Zeiss microscope (Zeiss Axioplan Fluorescence Microscope; Carl Zeiss, Germany) and analyzed off-line. Cortical thickness measurements (i.e. distance between the underlying white matter to the pia) were made similar to that reported elsewhere [37]. To reduce the potential for a masking effect of relatively small differences by the large variability between littermates, data was normalized to animals from the same litter. For 4',6-diamidino-2-phenylindole (DAPI) staining, sections were counterstained with DAPI $\left(1: 10^{4}\right)$ for $5 \mathrm{~min}$. at room temperature followed by a $1 \times$ PBS rinse 3 times for $5 \mathrm{~min}$. Deep layer TeA cell counts corresponded to the region of electrophysiological recordings.

\section{Analysis}

Signal acquisition and analysis was accomplished using Multi-clamp 700A and DIGIDATA 1322A 16-Bit data acquisition system and Clampex 9 programs allowing for data to be low-pass filtered at $2-8 \mathrm{kHz}$ and digitized at $\geq 10 \mathrm{kHz}$ (Axon Instruments, Inc. Forster City, CA, USA). Images analysis was accomplished using Image software (NIH). Data are expressed as mean \pm SEM. The statistical test and $\mathrm{p}$ value are noted when used. Two-tailed tests were used if not otherwise stated. Statistical analysis was accomplished with GraphPad software.

\section{Acknowledgements}

We would like to thank Sharmila Alams, Dr. Calvin Young, Dr. Keith Sharkey's Lab for providing technical assistance, and Dr. Wendy Edwards for helpful comments on an earlier version of this manuscript. This study was supported by grants from Canadian Institutes of Health Research, CIHR Regenerative Medicine Initiative and the Sinneave Family Foundation. 


\section{Author details}

${ }^{1}$ Department of Clinical Neurosciences, Hotchkiss Brain Institute, Faculty of Medicine, University of Calgary, Calgary, Alberta, T2N 4N1, Canada. ${ }^{2}$ Department of Psychology, Mount Royal University, Calgary, Alberta, T3E 6K6, Canada.

\section{Authors' contributions}

Conceived and designed the experiments: TC/BH. Developed and performed the experiments: TCNK/EB. Analyzed the data: TCNK. Wrote the paper: TC/ $\mathrm{BH}$. All authors read and approved the final manuscript.

Received: 14 January 2010 Accepted: 19 August 2010 Published: 19 August 2010

\section{References}

1. Amaral DG, Schumann CM, Nordahl CW: Neuroanatomy of autism. Trends Neurosci 2008, 31(3):137-145.

2. Kanner L: Autistic disturbances of affective contact. Nerv Child 1943, 2:217-250.

3. Dalton KM, Nacewicz BM, Johnstone T, Schaefer HS, Gernsbacher MA, Goldsmith $\mathrm{HH}$, Alexander AL, Davidson RJ: Gaze fixation and the neural circuitry of face processing in autism. Nat Neurosci 2005, 8(4):519-526.

4. Bryson SE, Zwaigenbaum L, Brian J, Roberts W, Szatmari P, Rombough V, McDermott C: A prospective case series of high-risk infants who developed autism. J Autism Dev Disord 2007, 37(1):12-24.

5. Landry R, Bryson SE: Impaired disengagement of attention in young children with autism. J Child Psychol Psychiatry 2004, 45(6):1115-1122.

6. Bryson SE: The Autistic Mind. The Neurobiology of Autism Baltimore, Maryland: The Johns Hopkins University PressBauman ML, Kemper TL 2005, 34-44.

7. van Kooten IA, Palmen SJ, von Cappeln P, Steinbusch HW, Korr H, Heinsen $H$, Hof PR, van Engeland H, Schmitz C: Neurons in the fusiform gyrus are fewer and smaller in autism. Brain 2008, 131(Pt 4):987-999.

8. Bailey A, Luthert P, Dean A, Harding B, Janota I, Montgomery M, Rutter M, Lantos P: A clinicopathological study of autism. Brain 1998, 121(Pt 5):889-905

9. Hazlett HC, Poe M, Gerig G, Smith RG, Provenzale J, Ross A, Gilmore J, Piven J: Magnetic resonance imaging and head circumference study of brain size in autism: birth through age 2 years. Arch Gen Psychiatry 2005, 62(12):1366-1376.

10. Schumann CM, Bloss CS, Barnes CC, Wideman GM, Carper RA, Akshoomoff N, Pierce K, Hagler D, Schork N, Lord C, et al: Longitudinal magnetic resonance imaging study of cortical development through early childhood in autism. J Neurosci 2010, 30(12):4419-4427.

11. Komura Y, Tamura R, Uwano T, Nishijo H, Kaga K, Ono T: Retrospective and prospective coding for predicted reward in the sensory thalamus. Nature 2001, 412(6846):546-549

12. Naya $Y$, Yoshida M, Miyashita Y: Backward spreading of memory-retrieval signal in the primate temporal cortex. Science 2001, 291(5504):661-664

13. Raz A, Buhle J: Typologies of attentional networks. Nat Rev Neurosci 2006, 7(5):367-379.

14. Moeller S, Freiwald WA, Tsao DY: Patches with links: a unified system for processing faces in the macaque temporal lobe. Science 2008 320(5881):1355-1359

15. Markram H, Rinaldi T, Markram K: The intense world syndrome - an alternative hypothesis for autism. Front Neurosci 2007, 1(1):77-96

16. Rinaldi T, Perrodin C, Markram H: Hyper-connectivity and hyper-plasticity in the medial prefrontal cortex in the valproic Acid animal model of autism. Front Neural Circuits 2008, 2:4

17. Schneider T, Przewlocki R: Behavioral alterations in rats prenatally exposed to valproic acid: animal model of autism. Neuropsychopharmacology 2005, 30(1):80-89.

18. Gogtay N, Giedd JN, Lusk L, Hayashi KM, Greenstein D, Vaituzis AC, Nugent TF, Herman DH, Clasen LS, Toga AW, et al: Dynamic mapping of human cortical development during childhood through early adulthood. Proc Natl Acad Sci USA 2004, 101(21):8174-8179.

19. Luna B, Garver KE, Urban TA, Lazar NA, Sweeney JA: Maturation of cognitive processes from late childhood to adulthood. Child Dev 2004, 75(5):1357-1372

20. Golarai G, Ghahremani DG, Whitfield-Gabrieli S, Reiss A, Eberhardt JL, Gabrieli JD, Grill-Spector K: Differential development of high-level visual cortex correlates with category-specific recognition memory. Nat Neurosci 2007, 10(4):512-522

21. Scherf KS, Behrmann M, Humphreys K, Luna B: Visual category-selectivity for faces, places and objects emerges along different developmental trajectories. Dev Sci 2007, 10(4):F15-30.

22. Shaw P, Eckstrand K, Sharp W, Blumenthal J, Lerch JP, Greenstein D, Clasen L, Evans A, Giedd J, Rapoport JL: Attention-deficit/hyperactivity disorder is characterized by a delay in cortical maturation. Proc Natl Acad Sci USA 2007, 104(49):19649-19654.

23. Bauman ML, Kemper TL: Neuroanatomic observations of the brain in autism: a review and future directions. Int J Dev Neurosci 2005, 23(23):183-187.

24. Lathe R: Autism, Brain, and Environment. Philadelphia, PA: Jessica Kingsley Publishers 2006.

25. Knudsen El: Sensitive periods in the development of the brain and behavior. J Cogn Neurosci 2004, 16(8):1412-1425.

26. Knudsen El, Heckman JJ, Cameron JL, Shonkoff JP: Economic, neurobiological, and behavioral perspectives on building America's future workforce. Proc Natl Acad Sci USA 2006, 103(27):10155-10162.

27. Rodier PM: Environmental causes of central nervous system maldevelopment. Pediatrics 2004, 113(4 Suppl):1076-1083

28. Hsieh J, Nakashima K, Kuwabara T, Mejia E, Gage FH: Histone deacetylase inhibition-mediated neuronal differentiation of multipotent adult neural progenitor cells. Proc Natl Acad Sci USA 2004, 101(47):16659-16664.

29. Balasubramaniyan V, Boddeke E, Bakels R, Kust B, Kooistra S, Veneman A, Copray S: Effects of histone deacetylation inhibition on neuronal differentiation of embryonic mouse neural stem cells. Neuroscience 2006, 143(4):939-951.

30. Akhtar MW, Raingo J, Nelson ED, Montgomery RL, Olson EN, Kavalali ET, Monteggia LM: Histone deacetylases 1 and 2 form a developmental switch that controls excitatory synapse maturation and function. $J$ Neurosci 2009, 29(25):8288-8297.

31. Jessberger S, Nakashima K, Clemenson GD Jr, Mejia E, Mathews E, Ure K, Ogawa S, Sinton CM, Gage FH, Hsieh J: Epigenetic modulation of seizureinduced neurogenesis and cognitive decline. J Neurosci 2007, 27(22):5967-5975.

32. Pellis SM, Pellis VC: Play fighting of rats in comparative perspective: a schema for neurobehavioral analyses. Neurosci Biobehav Rev 1998, 23(1):87-101.

33. Wagner GC, Reuhl KR, Cheh M, McRae P, Halladay AK: A new neurobehavioral model of autism in mice: pre- and postnatal exposure to sodium valproate. J Autism Dev Disord 2006, 36(6):779-793.

34. Rinaldi T, Kulangara K, Antoniello K, Markram H: Elevated NMDA receptor levels and enhanced postsynaptic long-term potentiation induced by prenatal exposure to valproic acid. Proc Natl Acad Sci USA 2007, 104(33):13501-13506.

35. Kolb B, Buhrmann K, McDonald R, Sutherland RJ: Dissociation of the medial prefrontal, posterior parietal, and posterior temporal cortex for spatial navigation and recognition memory in the rat. Cereb Cortex 1994, 4(6):664-680.

36. Chelazzi L, Miller EK, Duncan J, Desimone R: A neural basis for visual search in inferior temporal cortex. Nature 1993, 363(6427):345-347.

37. Kwon CH, Luikart BW, Powell CM, Zhou J, Matheny SA, Zhang W, Li Y, Baker SJ, Parada LF: Pten regulates neuronal arborization and social interaction in mice. Neuron 2006, 50(3):377-388.

38. Sia $Y$, Bourne JA: The rat temporal association cortical area $2(\mathrm{Te} 2)$ comprises two subdivisions that are visually responsive and develop independently. Neuroscience 2008, 156(1):118-128.

39. Chomiak T, Hu B: Latent Neurons in the Mature Mammalian Cortex: keeping the "old" cortex "young". Society for Neuroscience Program no 3710: 2007 San Diego, CA 2007.

40. Carleton A, Petreanu LT, Lansford R, Alvarez-Buylla A, Lledo PM: Becoming a new neuron in the adult olfactory bulb. Nat Neurosci 2003, 6(5):507-518.

41. Picken Bahrey HL, Moody WJ: Early development of voltage-gated ion currents and firing properties in neurons of the mouse cerebral cortex. Neurophysiol 2003, 89(4):1761-1773.

42. Bittigau P, Sifringer M, Genz K, Reith E, Pospischil D, Govindarajalu S, Dzietko M, Pesditschek S, Mai I, Dikranian K, et al: Antiepileptic drugs and apoptotic neurodegeneration in the developing brain. Proc Natl Acad Sci USA 2002, 99(23):15089-15094. 
43. Moore SJ, Turnpenny P, Quinn A, Glover S, Lloyd DJ, Montgomery T, Dean JC: A clinical study of 57 children with fetal anticonvulsant syndromes. J Med Genet 2000, 37(7):489-497.

44. Siemes H, Spohr HL, Michael T, Nau H: Therapy of infantile spasms with valproate: results of a prospective study. Epilepsia 1988, 29(5):553-560.

45. Coleman M, Betancur C: Introduction. The Neurology of Autism New York, NY: Oxford University Press, IncColeman M 2005, 3-39.

46. Chomiak T, Peters S, Hu B: Functional architecture and spike timing properties of corticofugal projections from rat ventral temporal cortex. $J$ Neurophysiol 2008, 100(1):327-335.

47. Mooney DM, Zhang L, Basile C, Senatorov W, Ngsee J, Omar A, Hu B: Distinct forms of cholinergic modulation in parallel thalamic sensory pathways. Proc Natl Acad Sci USA 2004, 101(1):320-324.

48. Hsieh J, Gage FH: Epigenetic control of neural stem cell fate. Curr Opin Genet Dev 2004, 14(5):461-469.

49. Caron C, Boyault C, Khochbin S: Regulatory cross-talk between lysine acetylation and ubiquitination: role in the control of protein stability. Bioessays 2005, 27(4):408-415.

50. Rosenbluth J: Subsurface cisterns and their relationship to the neuronal plasma membrane. J Cell Biol 1962, 13:405-421.

51. Bolton PF, Park RJ, Higgins JN, Griffiths PD, Pickles A: Neuro-epileptic determinants of autism spectrum disorders in tuberous sclerosis complex. Brain 2002, 125(Pt 6):1247-1255.

52. lida K, Otsubo H, Mohamed IS, Okuda C, Ochi A, Weiss SK, Chuang SH, Snead OC: Characterizing magnetoencephalographic spike sources in children with tuberous sclerosis complex. Epilepsia 2005, 46(9):1510-1517.

53. Meikle L, Talos DM, Onda H, Pollizzi K, Rotenberg A, Sahin M, Jensen FE, Kwiatkowski DJ: A mouse model of tuberous sclerosis: neuronal loss of Tsc1 causes dysplastic and ectopic neurons, reduced myelination, seizure activity, and limited survival. J Neurosci 2007, 27(21):5546-5558.

54. Wang Y, Greenwood JS, Calcagnotto ME, Kirsch HE, Barbaro NM, Baraban SC: Neocortical hyperexcitability in a human case of tuberous sclerosis complex and mice lacking neuronal expression of TSC1. Ann Neurol 2007, 61(2):139-152.

55. Ishibashi T, Dakin KA, Stevens B, Lee PR, Kozlov SV, Stewart CL, Fields RD: Astrocytes promote myelination in response to electrical impulses. Neuron 2006, 49(6):823-832.

56. Chomiak T, Hu B: What is the optimal value of the g-ratio for myelinated fibers in the rat CNS? A theoretical approach. PLoS One 2009, 4(11):e7754.

57. Markram K, Rinaldi T, La Mendola D, Sandi C, Markram H: Abnormal fear conditioning and amygdala processing in an animal model of autism. Neuropsychopharmacology 2008, 33(4):901-912.

58. Shi C, Davis M: Visual pathways involved in fear conditioning measured with fear-potentiated startle: behavioral and anatomic studies. J Neurosci 2001, 21(24):9844-9855.

59. Layton BS, Toga AW, Horenstein S, Davenport DG: Temporal pattern discrimination survives simultaneous bilateral ablation of suprasylvian cortex but not sequential bilateral ablation of insular-temporal cortex in the cat. Brain Res 1979, 173(2):337-340.

60. Campeau S, Davis M: Involvement of subcortical and cortical afferents to the lateral nucleus of the amygdala in fear conditioning measured with fear-potentiated startle in rats trained concurrently with auditory and visual conditioned stimuli. J Neurosci 1995, 15(3 Pt 2):2312-2327.

61. Zwaigenbaum L, Bryson S, Rogers T, Roberts W, Brian J, Szatmari P: Behavioral manifestations of autism in the first year of life. Int J Dev Neurosci 2005, 23(2-3):143-152.

62. Paxinos G, Watson C: The Rat Brain: In stereotaxic coordinates. New York: Academic Press, 41998.

63. Paxinos G: The rat nervous system. Amsterdam: Elsevier Academic Press, 3 2004.

64. Cruikshank SJ, Lewis TJ, Connors BW: Synaptic basis for intense thalamocortical activation of feedforward inhibitory cells in neocortex. Nat Neurosci 2007, 10(4):462-468.

65. Loscher W: Serum protein binding and pharmacokinetics of valproate in man, dog, rat and mouse. J Pharmacol Exp Ther 1978, 204(2):255-261.

66. Jeavons PM: Non-dose-related side effects of valproate. Epilepsia 1984, 25(Suppl 1):S50-55.

doi:10.1186/1471-2202-11-102

Cite this article as: Chomiak et al: Altering the trajectory of early postnatal cortical development can lead to structural and behavioural features of autism. BMC Neuroscience 2010 11:102.

\section{Submit your next manuscript to BioMed Central and take full advantage of:}

- Convenient online submission

- Thorough peer review

- No space constraints or color figure charges

- Immediate publication on acceptance

- Inclusion in PubMed, CAS, Scopus and Google Scholar

- Research which is freely available for redistribution

Submit your manuscript at www.biomedcentral.com/submit
Biomed Central 